\title{
A second look at religious orientation, social desirability, and prejudice
}

\author{
RONALD J. MORRIS, RALPH W. HOOD, JR., and P. J. WATSON \\ University of Tennessee at Chattanooga, Chattanooga, Tennessee
}

\begin{abstract}
In this study, which used a variety of measures of religious orientation, social desirability, and prejudice, religious orientation was correlated with self-reports of racial intolerance, and slightly negative, nonsignificant, and positive associations were observed for intrinsic, interactional, and extrinsic scales, respectively. Analysis of religious types further revealed that the intrinsic (I) and the indiscriminately antirelgious (IA) subjects were similar in their reduced prejudice relative to the extrinsic (E) and the indiscriminately proreligious (IP) subjects, who in turn did not differ. These comparisons remained essentially unchanged when sex and social desirability factors were controlled. Some data also suggested that IPs may be especially sensitive to social desirability factors, whereas Is may actually be more desirable socially. An awareness of the contrasts between Is and IPs may be crucial in research attempting to clarfiy the link between prejudice and religious commitments.
\end{abstract}

A principal concern of social scientists, including those in the psychology of religion, has been the nature and the causes of prejudice. Indeed, Batson and Ventis (1982) suggested that "this is probably the most extensively studied topic in the psychology of religion" (p. 235). Of foundational importance has been the need to establish the link between religion and prejudice; however, reviews of this extensive literature have revealed that definitive accomplishment of this most basic of tasks has proven to be an elusive goal.

Allport's work (e.g., Allport \& Ross, 1967) has influenced many of the more influential attempts at resolving this issue. He made a distinction between the apparently strong positive relationship between religion and prejudice and a more refined analysis in which a small core of honestly devout persons were found to be truly unprejudiced. These unprejudiced devout people had what Allport called an intrinsic orientation; " the intrinsically motivated lives his religion"' (Allport \& Ross, 1967, p. 434). In contrast, an extrinsic orientation revolves around a functional approach to religion; "the extrinsically motivated person uses his religion" (Alllport \& Ross, 1967, p.434). Allport's conclusion was that the direct relationship between religion and prejudice is generally true of the extrinsically motivated.

These speculations have received some substantiation in empirical research using Allport and Ross's (1967) intrinsic and extrinsic Religious Orientation Scales (e.g., Gorsuch \& Aleshire, 1974), but the supporting evidence has not gone unchallenged. Batson and his colleagues, for example, remain skeptical of attempts to use inverse correlations with prejudice to argue that the intrinsic scale cap-

Portions of this research were part of a master's thesis submitted by the senior author and approved by the Psychology Department of the University of Tennessee at Chattanooga. Address correspondence to P. J. Watson, Psychology Department, 350 Holt Hall, 615 McCallie Avenue, University of Tennessee at Chattanooga, Chattanooga, TN 37403. tures a prosocial motivation (Batson, Naifeh, \& Pate, 1978; Batson \& Ventis, 1982). The intrinsic scale, they claim, inadequately captures the full complexity of Allport's concern, which was with a sincere faith held in an open manner. Allport's operationalization theoretically focused more on commitment and less on openness, thus yielding an index of "compulsive, devout allegiance to institutional orthodoxy" (Batson \& Ventis, 1982, p. 155). Batson and Ventis's interactional "quest" measure of religiousness attempts to capture openness to change, positive evaluation of religious doubt, and confrontation with existential concerns; this quest orientation in fact predicts less prejudice. This alternative formulation further suggests that intrinsic believers wish only to appear unprejudiced, with intrinsic ties to less bigotry putatively depending upon a social desirability response set (see Batson et al., 1978).

In general terms, the present study sought to reexamine the issue of religious orientation, social desirability, and prejudice by looking at religious types in addition to the religious orientation scales themselves. Past researchers have had some success in better understanding the influence of religiousness on psychological functioning by using the Allport and Ross (1967) scales to sort intrinsic (I), extrinsic (E), indiscriminately proreligious (IP), and indiscriminately antireligious (IA) types (see, e.g., Donahue, 1985a; Hood, 1978). I-type individuals score above the sample-specific median only on the intrinsic scale, whereas the Es display an opposite pattern. IPs score above the median on both instruments, and IAs score below on both.

The Allport and Ross (1967) data seem to call for a reexamination of types. Their extrinsic and intrinsic items were combined into a single bipolar index of religious motivation. Also, across six separate samples of churchgoers, scores on this instrument were correlated with a number of prejudice measures, including an anti- 
Negro scale. The analysis was complicated by the IPs; however, when IP subjects were removed, four of the six correlations demonstrated intrinsicness to be linked with greater tolerance, with only one association revealing a significant effect in the opposite direction. Particularly striking in these results was the unreported fact that groups showing a relatively stronger relationship between intrinsicness and greater prejudice also had the highest percentage of IP scorers. Indeed, the rank order correlation between these two was significant $(\varrho=-.943, p<.05$, given the manner in which Allport \& Ross scored their data).

Batson and his colleagues suggested that variations in the Allport and Ross (1967) correlations were due to different group norms with regard to what was socially desirable. Another possibility is that samples showing the more indiscriminate characteristic were also samples in which classification of religious types was most problematic; that is, they contained the highest percentages of IPs, and valid identification of pure types was consequently made more difficult. This possibility was perhaps more likely because Allport and Ross employed a somewhat complicated procedure for identifying types that looked simultaneously at the relative responding to the two kinds of items.

An important stimulus in the development of the Allport and Ross (1967) scales was a curvilinear relationship typically found between church attendance and prejudice (Gorsuch \& Aleshire, 1974). The least prejudice was displayed by regular attenders, presumably Is, and by nonattenders, presumably IAs. Those whose attendance fell between these extremes were most prejudiced and presumably represented Es and IPs. Obtaining these outcomes for Es and IPs in the present project would reproduce the results of Allport and Ross, who had no IAs because of their method for breaking out types. Such IP data would also support the possibility that direct ties between intrinsicness and prejudice are mediated by an indiscriminately proreligious tendency that is associated with racial intolerance. Batson et al. (1978) reported sex differences in their prejudice and social desirability data, with the inverse link between these factors more evident in females; thus, the contribution of sex factor was also reanalyzed.

\section{METHOD}

\section{Participants}

The sample consisted of 379 undergraduate volunteers enrolled in introductory psychology courses. Of these 159 male and 220 female participants, $96 \%$ expressed nominal, primarily Protestant religious preference. The responses of 87 Black respondents were not included. All students received extra course credit for their contributions to the project.

\section{Questionnaires}

All subjects responded to the Allport and Ross (1967) Religious Orientation Scales and the Religious Life Inventory (Batson \& Ventis, 1982). The Religious Life Inventory consists of four subscales, including the interactional scale.

Social desirability was assessed using the Marlowe-Crowne (1964) Social Desirability Scale, and a modified version of a scale reported by Ehrlich (1973, p. 103) was employed to measure negative attitudes toward Blacks. This scale measures three components of prejudice: negative stereotypes, negative affect, and negative behavioral intentions. Each component consists of 20 items, balanced for direction (10 positive and 10 negative) and for salience. Two minor modifications we made in these scales involved use of a 5-point instead of the original 7-point Likert scale, and computation of scores such that a higher value indicated a more negative, prejudiced attitude. A total prejudice score was also obtained by summing a person's scores on all three components and dividing by the number of components. For all these measures, scores could range from 0 to 80 .

\section{Procedure}

Two large introductory psychology classes served as the initial pool for the survey. The questionnnaires were offered in class as an opportunity to gain extra course credit, and the survey was presented in two parts. The first part included the Religious Orientation Scales, the Religious Life Inventory, and the Marlowe-Crowne Social Desirability Scale. The second questionnaire included the prejudice measures and items from the Marlowe-Crowne scale rated for their relevance to each person's religious beliefs. Details concerning these religious relevance data have been published previously (Watson, Morris, Foster, \& Hood, 1986). In addition to the prejudice measures for Blacks, subjects were asked to use the same set of 60 items to rate their attitudes toward the mentally ill and homosexuals. This was done to help disguise the true focus of the study.

The administration of the pair of questionnaires was accomplished in two ways. One group $(n=185)$ completed the religious scales on the second day of class as part of normal course proceedings. The prejudice measures were then obtained about 3 months later as a take-home survey. The second group $(n=194)$ received instructions for the two questionnaires at the same time during the second day of class. The subjects were informed how to fill out the scales and then were told to respond to the surveys outside of class, returning them within the first week of class.

Variation in the administration of questionnaires was not originally planned and was done solely because of practical constraints. A careful check of the two data sets showed that the responses of the two groups of subjects were very similar. Except for one instance (to be discussed later), the pattern, magnitude, and direction of the correlations and the group differences of interest were statistically similar across the two administration conditions. For the purposes of the major analyses, therefore, the two groups were treated as a single sample.
Analyses
Our first statistical analyses examined possible social desirability and sex confounds of the relationship between religious orientation and prejudice. In the case of social desirability, the specific hypothesis based on Batson's work was that social desirability would be directly related to intrinsicness and inversely related to prejudice. Zero order correlations between the three measures of religious or orientation and prejudice were also examined. Additional hypotheses included the ideas that extrinsicness would be directly related to prejudice, in line with Allport's work, and that the interactional scale would display a link in the opposite direction, supporting Batson's previous research.
In the case of the intrinsic scale, Batson has suggested that an inverse relation between intrinsicness and prejudice should initially appear. This inverse relation is also implied by Allport's conceptualizations; however, past studies have not uniformly supported this position. Donahue (1985), for example, reported that in seven relevant samples, the mean correlation between the intrinsic and the anti-Black scales was only marginally negative, the average being -.09 . For all prejudice measures, not only the anti-Negro scale, the average correlation for eight samples was - 05 . Such nonsignificant outcomes would be expected if the tendency of I-type subjects to be less prejudiced were obscured by the greater intolerance of the IPs. In the final phase of the correlational part of the study, partials were computed between the three religious orientation scales and prejudice controlling for sex and/or social desirability. In the case of social desirability, Batson's arguments suggested that the direct relationship between extrinsicness and prejudice should remain, the inverse interactional tie should be unchanged, and any intrinsic connection with less bigotry should be eliminated and/or reversed. 
Table 1

Correlations of Prejudice Measures with Religious Scales, Sex, and Social Desirability, and Partial Correlations Controlling for Sex and/or Social Desirability

\begin{tabular}{|c|c|c|c|c|}
\hline \multirow[b]{2}{*}{ Scale } & \multicolumn{4}{|c|}{ Prejudice Measure } \\
\hline & $\begin{array}{l}\text { Negative } \\
\text { Stereotypes }\end{array}$ & $\begin{array}{c}\text { Negative } \\
\text { Affect }\end{array}$ & $\begin{array}{c}\text { Negative } \\
\text { Behavioral Intentions }\end{array}$ & Total \\
\hline \multicolumn{5}{|c|}{ Zero Order } \\
\hline Intrinsic & -.02 & -.01 & $-.12 \ddagger$ & -.06 \\
\hline Extrinsic & $.15 \S$ & $.15 \S$ & $.24 \S$ & $.20 \S$ \\
\hline Interactional & .02 & .02 & .03 & .03 \\
\hline Sex* & $-.17 \S$ & $-.16 \S$ & -.08 & $-.14 \S$ \\
\hline Social Desirability & $-.12 \ddagger$ & -.06 & $-.13 \ddagger$ & $-.11 \ddagger$ \\
\hline \multicolumn{5}{|c|}{ Controlling for Sex } \\
\hline Intrinsic & .00 & .01 & $-.11 \ddagger$ & -.04 \\
\hline Extrinsic & $.15 \S$ & $.14 \S$ & $.23 \S$ & $.20 \S$ \\
\hline Interactional & .00 & .00 & .02 & .01 \\
\hline \multicolumn{5}{|c|}{ Controlling for Social Desirability } \\
\hline Intrinsic & .00 & .01 & $-.09 \dagger$ & -.04 \\
\hline Extrinsic & $.14 \S$ & $.14 \S$ & $.22 \S$ & $.19 \S$ \\
\hline Interactional & .02 & .02 & .03 & .02 \\
\hline \multicolumn{5}{|c|}{ Controlling for Both Sex and Social Desirability } \\
\hline Intrinsic & .02 & .02 & $-.09 \dagger$ & -.02 \\
\hline Extrinsic & $.14 \S$ & $.14 \S$ & $.22 \S$ & $.19 \S$ \\
\hline Interactional & .00 & .00 & .02 & .01 \\
\hline
\end{tabular}

Note $-N=379$. $\quad$ *Inverse correlations with sex reveal a characteristic more strongly associated with females. $\quad \nmid p<.10$. $\ddagger p<.05$. $\S p<.01$.

A second major set of analyses dealt with the typologies. The four types were formed using the median split method with values equal to 31 and 28 for the intrinsic and extrinsic scales, respectively. This procedure yielded 127 Is, 125 Es, 64 Ips, and 63 IAs. The three previously mentioned hypotheses were tested using a set of orthogonal contrasts. Again, the suggestion was that Is and IAs would be lower than Es and IPs, but within these two pairs of groups no differences should appear. The planned contrasts were also carried out after group means were adjusted by controlling for variance explained by sex and social desirability.

\section{RESULTS}

Table 1 presents the major correlational findings of this study. As predicted extrinsicness was indicative of more prejudice, whereas social desireability was associated with less. Females were also more unbiased than males, but no tendency at all was apparent for the interactional scale to be associated with less racial intolerance. The intrinsic scale was not generally related to reduced prejudice; interestingly, the average of the obtained correlations was -.0525 , virtually identical to the average value reported by Donahue (1985). A significant negative correlation was observed, however, between the intrinsic scale and the behavioral intentions component of Ehrlich's (1973) questionnaire. Partialling out sex and/or social desirability produced no major changes in the data, although the inverse intrinsic tie with negative behavioral intentions was slightly diminished by controlling for social desirability.

Implied in Batson's work is the idea that females are more likely to display a social desirability response and that sex differences in prejudice are mediated by this factor. In the present sample, females did score slightly higher on the Marlowe-Crowne scale $(r=-.09, p<.05$, one-tailed test), but partial correlations controlling for social desirability failed to alter the statistical significance of any sex relationship with prejudice. Furthermore, a direct comparison of separate male and female correlations between social desirability and prejudice revealed absolutely no evidence of a difference (all $z \mathrm{~s}$ between 0 and $0.76, p \mathrm{~s}>.20$ ). Thus, no evidence supported the notion that sex differences in prejudice were explicable in terms of social desirability response sets.

Table 2 presents the results of the planned group contrasts and demonstrates that all predictions for each of the prejudice measures were confirmed. In each instance, Is and IAs displayed less racial intolerance than

Table 2

Mean and Adjusted Mean* Prejudice Scores for Intrinsic (I), Extrinsic (E), Indiscriminately Proreligious (IP), and Indiscriminately Antireligious (IA) Types, and

Statistical Analyses of Planned Contrasts

\begin{tabular}{|c|c|c|c|c|c|c|c|}
\hline \multirow[b]{2}{*}{$\begin{array}{l}\text { Prejudice } \\
\text { Measure }\end{array}$} & \multicolumn{4}{|c|}{ Religious Orientation Types } & \multicolumn{3}{|c|}{ Statistical Analyses } \\
\hline & $\begin{array}{c}I \\
(N=127)\end{array}$ & $\begin{array}{c}\text { IA } \\
(N=63)\end{array}$ & $\begin{array}{c}\mathrm{E} \\
(N=125)\end{array}$ & $\begin{array}{c}\text { IP } \\
(N=64)\end{array}$ & Contrast & $t$ & $\begin{array}{c}\text { Adjusted } \\
t^{* *}\end{array}$ \\
\hline $\begin{array}{l}\text { Negative } \\
\text { Stereotype }\end{array}$ & $\begin{array}{c}36.80 \\
(37.25)\end{array}$ & $\begin{array}{c}36.56 \\
(36.66)\end{array}$ & $\begin{array}{c}38.94 \\
(38.21)\end{array}$ & $\begin{array}{c}40.98 \\
(41.40)\end{array}$ & $\begin{array}{l}\text { (I,IA) vs. (E,IP) } \\
\text { I vs. IA } \\
\text { E vs. IP }\end{array}$ & $\begin{array}{c}-2.426 \ddagger \\
.129 \\
-1.072\end{array}$ & $\begin{array}{r}-2.139 \ddagger \\
.308 \\
-1.676 \dagger\end{array}$ \\
\hline $\begin{array}{l}\text { Negative } \\
\text { Affect }\end{array}$ & $\begin{array}{c}35.91 \\
(36.13)\end{array}$ & $\begin{array}{c}35.48 \\
(35.74)\end{array}$ & $\begin{array}{c}37.98 \\
(37.44)\end{array}$ & $\begin{array}{l}38.77 \\
39.15\end{array}$ & $\begin{array}{l}\text { (I,IA) vs. }(\mathrm{E}, \mathrm{IP}) \\
\text { I vs. IA } \\
\mathrm{E} \text { vs. IP }\end{array}$ & $\begin{array}{c}-2.074 \ddagger \\
.239 \\
-.428\end{array}$ & $\begin{array}{r}-1.840 \dagger \\
.213 \\
-.932\end{array}$ \\
\hline $\begin{array}{l}\text { Negative } \\
\text { Behavioral } \\
\text { Intention }\end{array}$ & $\begin{array}{c}19.03 \\
(19.46)\end{array}$ & $\begin{array}{c}21.92 \\
(21.72)\end{array}$ & $\begin{array}{c}25.98 \\
(25.57)\end{array}$ & $\begin{array}{c}25.83 \\
(25.97)\end{array}$ & $\begin{array}{l}\text { (I,IA) vs. }(\mathrm{E}, \mathrm{IP}) \\
\text { I vs. IA } \\
\text { E vs.IP }\end{array}$ & $\begin{array}{r}-3.346 \S \\
-1.258 \\
.065\end{array}$ & $\begin{array}{l}-3.193 \S \\
-.969 \\
-.175\end{array}$ \\
\hline Total & $\begin{array}{c}30.58 \\
(30.95)\end{array}$ & $\begin{array}{c}31.32 \\
(31.37)\end{array}$ & $\begin{array}{c}34.30 \\
(33.74)\end{array}$ & $\begin{array}{c}35.19 \\
(35.51)\end{array}$ & $\begin{array}{l}\text { (I,IA) vs. }(\mathrm{E}, \mathrm{IP}) \\
\text { I vs. IA } \\
\text { E vs. IP }\end{array}$ & $\begin{array}{l}-2.976 \S \\
-.407 \\
-.496\end{array}$ & $\begin{array}{c}-2.735 \S \\
-.978 \\
-2.34\end{array}$ \\
\hline
\end{tabular}

*Adjusted means represent prejudice scores controlling for sex and social desirability and are found in the parentheses below each mean. **Adjusted $t$ values reflect analyses of the planned contrasts after controlling for sex and social desirability. $\quad \nmid p<.10$. $\ddagger p<.05$. $\S p<.01$. 
Table 3

Social Desirability Scores of Intrinsic (I), Extrinsic (E), Indiscriminately Proreligious (IP), and Indiscriminately Antireligious (IA) Types for Samples that took the Social Desirability Scale at the Same Time as the Intrinsic Scale or after a 3-Month Delay

\begin{tabular}{ccccr}
\hline & \multicolumn{4}{c}{ Religious Orientation Type } \\
\cline { 2 - 5 } Measure & I & E & IP & IA \\
\hline \multicolumn{5}{c}{ Same-Time Group } \\
$M$ & 15.80 & 13.08 & 15.75 & 12.27 \\
$N$ & 66 & 63 & 28 & 37 \\
\multicolumn{5}{c}{ 3-Month-Delay Group } \\
$M$ & 15.33 & 13.92 & 12.81 & 13.81 \\
$N$ & 61 & 62 & 36 & 26 \\
\hline
\end{tabular}

Es and IPs. The two types within each pair did not differ, and controlling for sex and social desirability produced no noteworthy changes.

Type differences in social desirability are summarized in Table 3. These data were the one instance in which the administration procedure seemed to produce an important effect; thus, Marlowe-Crowne scores are listed separately for the same-time and the 3-month-delay groups. No overall differences were apparent for the two administration procedures $[F(1,371)=0.06, p>.50]$, but a religious type effect was obtained $[F(1,371)=5.42$, $p<.01$ ], with Is scoring higher than Es and IAs. A significant interaction was also observed $[F(1,371)=$ $2.65, p<.05$ ], demonstrating that Is did not differ across administration conditions $[t(125)=.495, p>.50]$, whereas IPs displayed higher Marlowe-Crowne values under the same-time procedure $[t(62)=2.272, p<.05]$. The correlations between the intrinsic and MarloweCrowne scales also varied as a function of the two conditions, being significant for the same-time group $(r=.33$, $p<.01)$ but not for the 3-month-delay group $(r=.07$, $p>.30)$.

\section{DISCUSSION}

Results from the present study yielded a number of findings with implications for studying the relation between religious orientation, prejudice, and social desirability. First, the data demonstrated that Batson and Ventis's (1982) interactional scale does not invariably predict less racial prejudice, an observation that proves problematic for any claim that a quest orientation, at least as measured by this instrument, is necessarily associated with greater open-mindedness and tolerance. Second, as in past research, sex differences in prejudice were discovered; but the more unbiased attitudes of females did not seem easily explained in terms of a social desirability response set. Third, extrinsicness was reconfirmed as a correlate of racial intolerance. Finally, the data once again demonstrated the need to examine religious orientation types. IAs and Is expressed less prejudice than Es and IPs. The usually observed failure of the intrinsic scale and related concepts to exhibit significant associations with less bigotry may therefore reflect the tendency of high intrinsicness to be associated with greater prejudice in IPs and of low intrinsicness to be associated with the tolerance of IAs.

That the lower level of prejudice in Is could be explained by a social desirability confound seemed unlikely. First, controlling for sex and social desirability resulted in no major changes in the planned comparisions of Is and IAs with Es and IPs. More importantly, controlling for these factors had no effect at all on the similar attitudes expressed by Is and IAs. Finally, contrasts in social desirability across the two administration conditions may help clarify I and IP responses to Marlowe-Crowne scale. If Is wished to appear more socially desirable than they actually are, then presumably they would display higher social desirability scores in a situation in which this need was made more salient. At least conceivably, the same-time condition was such a situation because the issues of racial prejudice and religious beliefs were brought together more or less simultaneously. However, the IPs, not the Is, displayed greater Marlowe-Crowne values during this same-time procedure, and Is had scores that were equally high across the two conditions.

Thus, IPs rather than Is may be more concerned about appearing socially desirable. For Is, elevated Marlowe-Crowne values may indicate that they are reporting something that is factually true-not that they want to appear socially desirable, but rather that they are more desirable socially. Such an interpretation would be consistent with the work of McCrea and Costa (1983), which indicated that the Marlowe-Crowne is contaminated by a tendency to measure psychological adjustment. In addition, Marlowe-Crowne items are evaluated as relevant to religious commitments, and these evaluations are directly related to both the intrinsic and social desirability scales (Watson et al., 1986). Taken together, these considerations suggest that the Marlowe-Crowne and intrinsic scales may be sensitive to normative values associated with desirable sociality and that this sensitivity is particularly evident in Is.

\section{REFERENCES}

AllPort, G. W., \& Ross, J. M. (1967). Personal religious orientation and prejudice. Journal of Personality \& Social Psychology, 5, 432-443.

Batson, C. D., NaIfeh, S. J., \& PATe, S. (1978). Social desirability, religious orientation and racial prejudice. Journal for the Scientific Study of Religion, 17, 31-41.

Batson, C. D., \& Ventis, W. L. (1982). The religious experience. New York: Oxford University Press.

Donahue, M. J. (1985). Intrinsic and extrinsic religiousness: The empirical research. Journal for the Scientific Study of Religion, 24, 418-423.

EHRLICH, H. J. (1973). Social psychology and prejudice. New York: Wiley.

Gorsuch, R. L., \& Aleshire, D. (1974). Christian faith and ethnic prejudice: A review and interpretation of research. Journal for the Scientific Study of Religion, 13, 281-307.

Hood, R. W., JR. (1978). The usefulness of the indiscriminately pro and anti categories of religious orientation. Journal for the Scientific Study of Religion, 17, 419-431.

MARLOWE, D., \& CROWNE, D. (1964). The approval motive. New York: Wiley.

McCREA, R. R., \& CostA, P. T. (1983). Social desirability scales: More substance than style. Journal of Consulting \& Clinical Psychology, 51, 882-888.

Watson, P. J., Morris, R. J., Foster, J. E., \& HoOd, R. W., JR. (1986). Religiosity and social desirability. Journal for the Scientific Study of Religion, 25, 215-232.

(Manuscript received July 8, 1988.) 